\title{
Utilization of Oilseed Crops for On-farm Energy Security
}

\author{
Suraj Adhikari and Prabodh Illukpitiya*
}

\author{
Department of Agricultural and Environmental Sciences, Tennessee State University, 3500 John A. Merritt \\ Blvd, Nashville, TN 37209, USA
}

\begin{abstract}
There has been considerable interest focused on the investment for the production of oilseed crops for biodiesel. The advance research is needed to provide knowledge needed for the feasible way of adaptation of oilseed crops for biodiesel. Among the various oilseed crops produced, sunflower is a prominent summer crop that can be used to produce on-farm biodiesel for energy security. The objective of this paper is to estimate the overall economic benefits of biodiesel production from sunflower under small scale settings. The economic viability on production of biodiesel and its market opportunity to the farmers were investigated at its 3 different production stages namely; seed, oil and seed meal, and biodiesel production. The study was based on three different on-farm biodiesel extraction scenarios. For example, the seed press and biodiesel extractor can be operated at three different rates (low, medium and high). Feedstock production, capital investment for biodiesel units and operations costs were considered for the analysis. To calculate cost and revenue in annual equivalent terms, the present values of all costs and revenues over the useful life was transformed into an equivalent annuity. Analysis shows that biodiesel production from sunflower production could generate positive net returns under various scenarios. The analysis per volume basis showed that the production cost of biodiesel from sunflower oil to producer was between $\$ 2.00$ to $\$ 3.21 / \mathrm{gal}$ when revenue from seed meal was accounted. The estimated break-even price of sunflower seed range from $\$ 0.18$ to $0.26 / \mathrm{kg}$ depending upon sunflower yield. The findings of this research further improve the understanding of growing sunflower as an oilseed crops and on-farm processing of oil for local biodiesel production that could play vital role in improving farm income as well as sustainable and independent energy for small farmers.
\end{abstract}

Keywords: Biodiesel, Seed meal, Seed press, Small farms, Summer oilseed crops, Sunflower.

\section{INTRODUCTION}

In recent years rapid growth in the production and consumption of bioenergy has been witnessed for powering combustion engines, industrial purposes and other various fields. In the long-term one can expect, in relevant areas, a shift from petroleum- and gas-based raw materials to bio-based. World energy demand continues to rise hence the most feasible way to meet this growing demand is by using alternative fuels. One such fuel that exhibits great potential is biofuel, in particular biodiesel [1]. The term biofuel can refer to liquid or gaseous fuels for the transport sector that are predominantly produced from biomass [2]. Reasons for using biofuels include energy security, environmental concerns, foreign exchange savings, and socioeconomic issues related to the rural sector [3]. There is a growing trend toward using modern technologies and efficient bioenergy conversion with a range of biofuels, which are becoming cost-wise competitive with fossil fuels [4]. Biodiesel offers the advantage of being able to be produced locally with limited technical skills and requiring a modest capital investment [5].

Sunflower (Helianthus annuus L.) has been gaining popularity as a feedstock crop for biodiesel since it

*Address correspondence to this author at the Department of Agricultural and Environmental Sciences, Tennessee State University, 3500 John A. Merritt Blvd, Nashville, TN 37209, USA; Tel: (615) 963-1877;

E-mail: pillukpi@Tnstate.edu shares several positive agronomic features with other common oil crops such as canola and soybean; yields well in a variety of conditions, and can be grown easily and profitably at both small farm and large field scales [6]. Sunflower is an important agricultural crop choice for US producers in the northern plains of the Dakotas to the panhandle of Texas. Its seed contains high amount of oil, for example under average yield situation, sunflower produce $672.5 \mathrm{~kg}$ of oil per hectare, considerably more than soybeans. There is a great deal of interest from local growers for construction of small processing facilities for sunflower biodiesel production [7]. On-farm oilseed processing and biodiesel production is often considered as a possible strategy to mitigate the impact of rising fuel prices [8]. Momentum is gaining for raising oilseed crops like sunflowers, canola, and soybeans to make biodiesel for fuel and oilseed meal for livestock, in addition to being sold as crops [9]. Presently, most U.S. based commercial sunflower production is in the Great Plains states of Colorado, Kansas, Minnesota, Nebraska, North Dakota, South Dakota and Texas [10]. In 2013, average U.S. yield of sunflower seed was $1544.5 \mathrm{~kg} / \mathrm{ha}$ [11]. Sunflower is adapted to Tennessee conditions, even though its primary production is in the western and upper Great Plain [12].

The feasibility of farm-scale biodiesel production from oilseed crops has been investigated for oilseedproducing regions [8] and processing oilseeds into biodiesel is an emerging area of knowledge and 


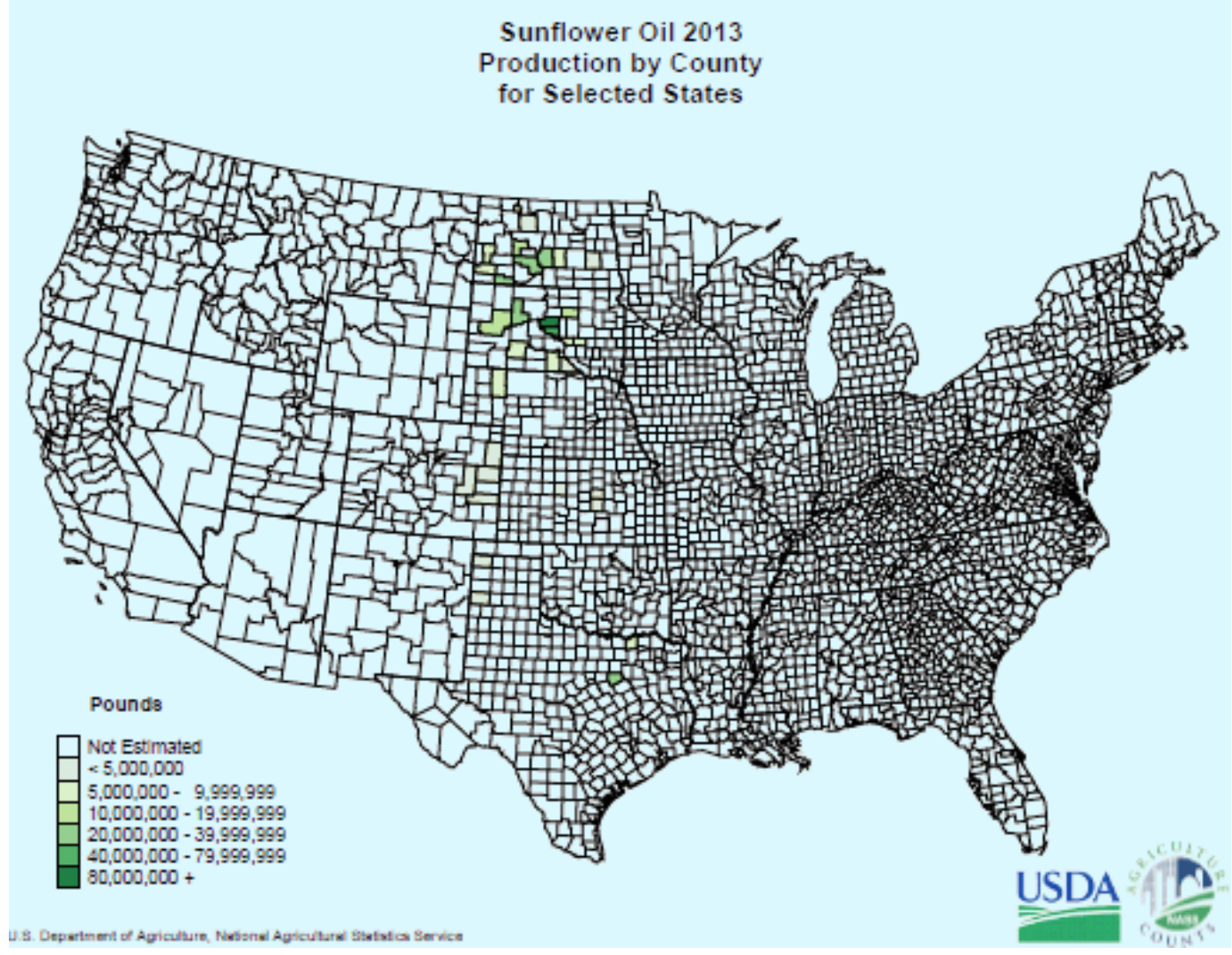

Figure 1: Sunflower oil production in selected States [10].

experience. According to University of Vermont Extension (UVM), production of oilseed crops is rare and small-scale oilseed and on-farm biodiesel production remain largely unproven concepts. Farmers generally perceive that they have neither the necessary equipment nor experience to raise these crops. However, if farmers could grow and harvest oilseed crops, press the seeds into vegetable oil and oilseed meal, and process the oil into biodiesel, they could independently produce both liquid biofuel and livestock feed. Early experience with pressing oilseeds into vegetable oil and meal has shown that on-farm oil and meal production is technically feasible [13].

Production cost and returns are key concerns in decision making in investment of on-farm biodiesel production. Understanding the key economic issues relating to biodiesel production can help potential biodiesel producers make more informed decisions [14]. The pattern of the price paid by farmers for diesel fuel from 1998 to 2008 suggests that the price of diesel fuel will continue to increase in coming years [15]. According to USDA statistics the price paid by farmers for diesel fuel increased by $192 \%$ from April 2003 to April 2008. Farm diesel prices have increased over $300 \%$ since the mid 1990's and $100 \%$ in the last three years [16]. According to Bachmann [17] most oil processing in the U.S. is done on a large, industrial scale using proprietary processes. But in recent years, interest in farm-scale extraction technologies has increased which might be the result of rise in fuel and feed costs and increasing interest of producers in making biodiesel and feed from oilseeds [18].

This study focused sunflower as a major feedstock to be used for on-farm processing because it is one of the important and common oilseed crops produced in the southern planes in the U.S. Given the importance and need for the growth of biofuel and bio-based product market, it is hypothesized that sunflower as an oilseed crop provide positive economic benefits and energy security for farmers. The major objective of this paper is to evaluate the economic feasibility of producing biodiesel from sunflower under small-scale setting.

\section{METHODOLOGY}

\section{Economic Model}

When overall plant cost estimation is required, inspecting the individual cost per year is not adequate because some operations are not performed regularly 
and uniformly year after year and therefore, annual cost may differ over the life span of the project. From an economic point of view, the overall approach is to estimate the average annual cost and returns over the entire economic life of the project, which allows direct comparison among different scenarios. To calculate cost and revenue in annual equivalent terms, the present values of all costs and revenues over the useful life of the crop is transformed into an equivalent annuity [19]. As the project studies the economic viability of production and processing of sunflower at three different stages (production of seed, processing into sunflower oil and seed meal, and processing oil into biodiesel), benefit:cost model was adopted in estimating annual equivalent cost and revenues.

Accordingly,

$B / C=P V B / P V C$

Where, $P V B=$ Present value of benefits and $P V C=$ Present value of cost.Similarly,

$P V B=\sum$ Benefits $/(1+r)^{t}$

Where, $r=$ Discount factor and $t=$ Time period.

$P V C=\sum$ Costs $/(1+r)^{t}$ Where, $r=$ Discount factor and $t=$ Time period.

Accordingly, Annual Equivalent Cost (AEC) and Annual Equivalent Revenue (AER) were estimated as:

$$
\begin{aligned}
& A E C=\frac{P V_{c} \times i}{1-(1+i)^{-n}} \\
& A E R=\frac{P V_{R} \times i}{1-(1+i)^{-n}}
\end{aligned}
$$

In this analysis, $n$ was assumed equal to 15 years and $i$ equal to average historical discount rate from Federal Reserve. PVC and PVB are the present value of cost and revenue respectively over the 15 year period. Here the cost implies to the cost of production of feedstock such as seed, fertilizer, machinery, and processing costs such as seed press, biodiesel processor and required chemicals.

$P V=\sum_{t=0}^{n} F V_{n} \times(1+i)^{-n}$

Information on farm level costs and returns for sunflower production were obtained from secondary data sources. Information were collected on the quantity of crop output, inputs such as land area under cultivation, labor and other inputs such as inorganic fertilizer, and pesticides. Several production cost estimation (i.e. machinery cost, interest, insurance payment etc.) required economic engineering method. Specific formulas were developed in estimating costs for these categories. Data required for economic engineering approach were gathered mainly from secondary sources (i.e. enterprise budget from Texas, Oklahoma, and Colorado). Accordingly, the cost of production of sunflower was found to be $\$ 374 /$ ha. The baseline average yield for sunflower was assumed to be $2,381 \mathrm{~kg} / \mathrm{ha}$. For the purpose of the baseline scenarios seed, meal and oil prices were obtained from authentic sources. Based on historical data USDANASS [11], the market price of sunflower seed price was taken as $\$ 500 / \mathrm{mt}$. Based on information from National Sunflower Association [7], the market price of sunflower seed meal was taken as $\$ 202 / \mathrm{mt}$. The estimated sunflower oil price was $\$ 1.48 / \mathrm{kg}$. The price of biodiesel sold or value of biodiesel purchases replaced with the on- farm production was assumed to be $\$ 4.57 /$ gal [20].

The study was based on three different on-farm biodiesel production facilities. The seed press and biodiesel extractor used were differentiated into three categories on the basis of its operation speed/rates (low, medium and high). Under low, medium and high speed rate (also known as efficiency categories of $68.5 \%, 55.1 \%$ and $53.6 \%$ based on the amount of oil can be extracted), the amount of seeds to be processed were $0.96,3.05$ and $5.20 \mathrm{~kg} / \mathrm{ha}$. Accordingly, the amount of biodiesel to be processed were 139, 113 and 109.8 gallon/ha respectively for low, medium and high efficiency rates. The breakeven price of sunflower seed was estimated by dividing the total cost of production by the total quantity of oilseed produced. The breakeven price of sunflower oil extracted was estimated by dividing the total cost of production including processing of oil by the total quantity of oil extracted from the oilseed press.

In this research, small scale biodiesel processing unit with annual capacity of 1,500 gallons for the production of biodiesel was considered. The capital cost was based on market price of a common type of biodiesel unit and variables costs for biodiesel processing include chemical costs for methanol, potassium hydroxide, fuel, labor, electricity and annual repair and maintenance. 
Equipment costs primarily comprise capital costs for seed press, biodiesel processor, methanol recovery system and installation. The total equipment cost after considering $25 \%$ US government subsidy on machinery and equipment was taken into account. Seed pressing and processing of sunflower oil to biodiesel requires chemicals, electricity and labor. Costs of methanol and potassium hydroxide were based on market prices. Accordingly, estimated cost of methanol required to process sunflower oil from a hectare of sunflower was $\$ 89.42$ (based on its market price $\$ 0.79 /$ gal of methanol). Similarly, cost for potassium hydroxide to process a hectare of sunflower was of $\$ 32.45$ (based on its market price of $\$ 0.29 / \mathrm{gal})$.

\section{RESULTS AND DISCUSSION}

Major products from sunflower include sunflower seed, oil and/or processing of oil to biodiesel. Table 1 shows the details of sunflower seed production costs. Accordingly total variable costs were $\$ 488.47 /{\mathrm{ha} \mathrm{yr}^{-1}}^{-1}$

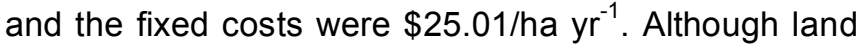
rent costs are part of fixed expenses, land rent was excluded from the analysis assuming that farmers own the land. Accordingly total feedstock production costs was 513.5/ha $\mathrm{yr}^{-1}$. Among the category of variable costs, fertilizer, herbicide, harvesting and seed cost account the major expenses with $\$ 120.56$, \$76.34, $\$ 66.60$ and $\$ 59.43 /$ ha $^{-1} r^{-1}$ respectively.

Table 1: Sunflower Feedstock Production Cost

\begin{tabular}{|c|c|c|}
\hline Cost of Feedstock & Average Cost & Annual Equivalent Cost \\
\hline \hline Seed & $\$ 59.43$ & $\$ 13.30$ \\
\hline Insecticide & $\$ 17.46$ & $\$ 55.62$ \\
\hline Herbicides & $\$ 76.34$ & $\$ 19.53$ \\
\hline Pesticides & $\$ 26.81$ & $\$ 87.84$ \\
\hline Fertilizers & $\$ 120.56$ & $\$ 37.32$ \\
\hline Appl. of pesticides & $\$ 51.23$ & $\$ 48.52$ \\
\hline Harvesting cost & $\$ 66.60$ & $\$ 7.72$ \\
\hline Hauling cost & $\$ 10.59$ & $\$ 7.22$ \\
\hline Labor & $\$ 9.91$ & $\$ 23.84$ \\
\hline Fuel & $\$ 32.73$ & $\$ 12.23$ \\
\hline Repair \& maintenance & $\$ 16.79$ & $\$ 18.29$ \\
\hline Machinery and equipment & $\$ 25.10$ & $\$ 374.15$ \\
\hline Total & $\$ 513.56$ & \\
\hline
\end{tabular}

Table 2: Processing Costs of Sunflower Seed to Biodiesel

\begin{tabular}{|c|c|c|c|c|c|c|}
\hline \multirow{2}{*}{ Category } & \multicolumn{5}{|c|}{ Yield Scenario/ Medium Rate Processor } \\
\cline { 2 - 7 } & $\begin{array}{c}\text { High } \\
\text { Average } \\
\text { Cost }\end{array}$ & $\begin{array}{c}\text { Annual Equivalent } \\
\text { Cost }\end{array}$ & $\begin{array}{c}\text { Average } \\
\text { Cost }\end{array}$ & $\begin{array}{c}\text { Medium } \\
\text { Annual } \\
\text { Cost }\end{array}$ & \multicolumn{2}{c|}{ Low } \\
\hline \hline Depreciation & $\$ 87.25$ & $\$ 63.41$ & $\$ 74.05$ & $\$ 53.09$ & $\$ 61.68$ & $\begin{array}{c}\text { Annual Equivalent } \\
\text { Cost }\end{array}$ \\
\hline $\begin{array}{c}\text { Potassium } \\
\text { Hydroxide }\end{array}$ & $\$ 38.24$ & $\$ 27.42$ & $\$ 32.45$ & $\$ 23.27$ & $\$ 27.03$ & $\$ 19.38$ \\
\hline $\begin{array}{c}\text { Methanol } \\
\text { Electricity }\end{array}$ & $\$ 105.36$ & $\$ 75.54$ & $\$ 89.42$ & $\$ 64.11$ & $\$ 74.49$ & $\$ 53.41$ \\
\hline Labor & $\$ 30.00$ & $\$ 60.78$ & $\$ 71.94$ & $\$ 51.58$ & $\$ 59.93$ & $\$ 42.97$ \\
\hline $\begin{array}{c}\text { Total processing } \\
\text { cost }\end{array}$ & $\$ 345.61$ & $\$ 247.80$ & $\$ 297.86$ & $\$ 213.56$ & $\$ 253.13$ & $\$ 21.51$ \\
\hline
\end{tabular}


Table 3: Sunflower Oil, Biodiesel and Seed Meal Yield under Different Processing Speeds

\begin{tabular}{|c|c|c|c|}
\hline \multirow{2}{*}{ Category } & \multicolumn{3}{|c|}{ Processing Speeds } \\
\cline { 2 - 4 } & Low Rate Processor & Medium Rate Processor & High Rate Processor \\
\hline \hline Oil yield (gal/ha) & 154.66 & 125.56 & 121.99 \\
\hline Biodiesel (gal/ha) & 139.19 & 113.00 & 109.79 \\
\hline Meal yield (kg/ha) & 1721.56 & 1858.26 & 1873.84 \\
\hline
\end{tabular}

The processing costs include investment for machinery and associated variable costs for chemicals, electricity labor etc. The straight line method was used to calculate depreciation on fixed assets. Table 2 shows the processing costs of biodiesel. The average depreciation cost per year was $\$ 63.41$ and $\$ 44.23$ in high and low yield categories respectively. Similar trend was observed for the cost of chemicals and electricity. Potassium hydroxide and Methanol were the chemicals that were used in the processing of sunflower oil to biodiesel. The cost of the labor accounted \$30/ha irrespective the different yield scenarios. After calculating all the processing cost on different headings, it was clear that the processing cost was directly associated with the seed yield. The total processing cost for the higher, medium and lower yield was $\$ 247.80, \quad \$ 231.56$ and $\$ 181.49 / \mathrm{ha} \mathrm{yr}^{-1}$ respectively.

Table 3 shows the yield of the sunflower oil, biodiesel and seed meal (based on average sunflower yield) on three different processing rates (low, medium and high) For example amount of seed that can be processed under the above different operating rates were $0.96,3.05$ and $5.21 \mathrm{~kg} / \mathrm{ha}$ respectively. According to the analysis, the production of sunflower oil and biodiesel was higher under lower rate processor and lower in high rate processor. However, total yield of seed meal was higher under high rate processor due to higher amount of leftover oil in seed meal.

Production of sunflower seed meal is an important by-product in oil/biodiesel production process. Figure 2 shows details of meal yield and associated revenue from meal.

Table 4 shows the overall net return from biodiesel production. The total revenue was estimated by considering revenue from biodiesel as well as seed meal. The estimated total revenue under medium rate of processing was $\$ 785.98, \$ 667.06$ and $\$ 555.68 / \mathrm{ha}$ $\mathrm{yr}^{-1}$ respectively for low, medium and high yield scenarios. Similarly, net returns from biodiesel production from sunflower was $\$ 169.96, \$ 85.28$ and

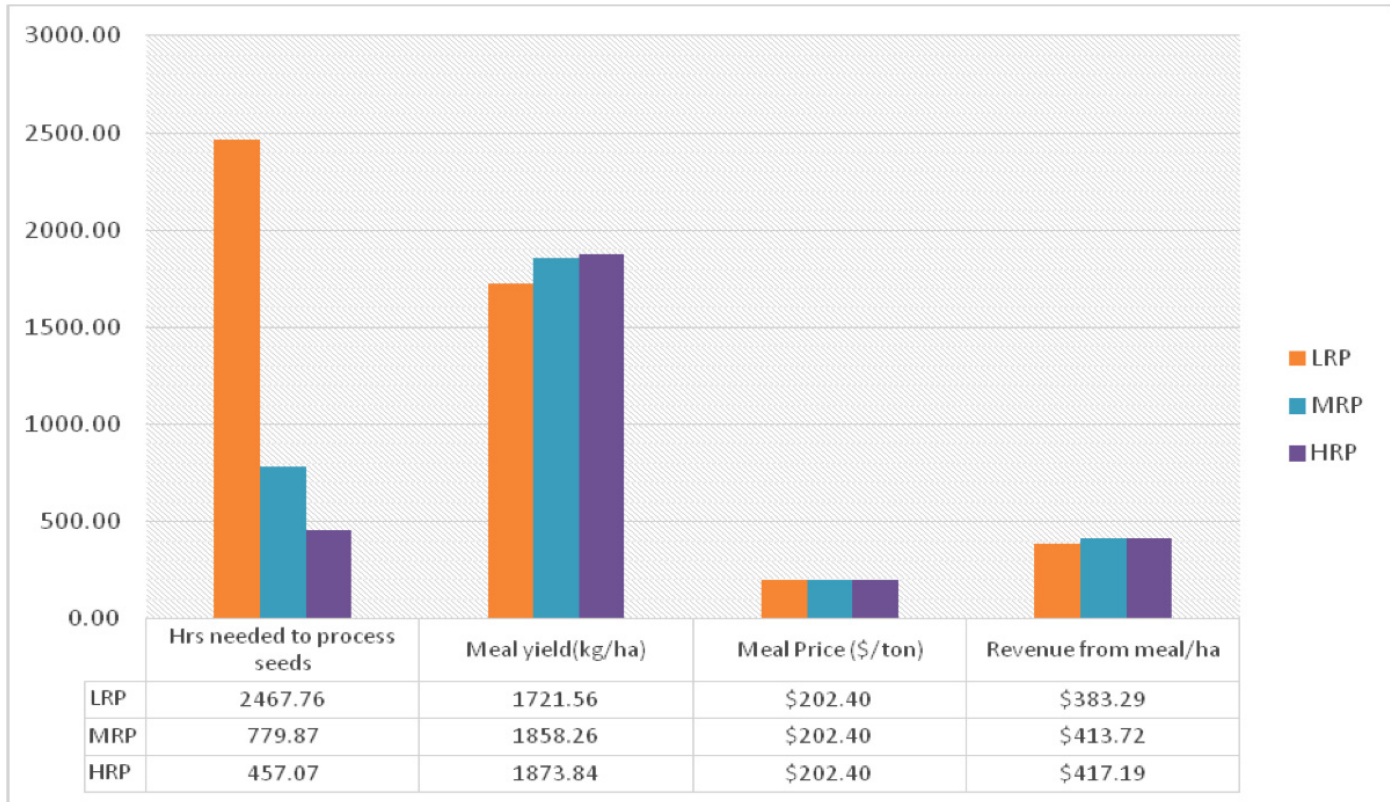

Figure 2: Total seed meal and revenue under various processing rates.

Note: LRP: Low processing rate, MRP: Medium processing rate and HRP: High processing rate. Accordingly revenue from seed

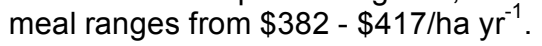


Table 4: Net Return from Biodiesel Production

\begin{tabular}{|c|c|c|c|c|c|c|}
\hline Category & \multicolumn{4}{|c|}{ Yield Scenario/ Medium Rate Processor } \\
\hline & \multicolumn{2}{|c|}{ High } & \multicolumn{2}{c|}{ Medium } & \multicolumn{2}{c|}{ Low } \\
& Average & $\begin{array}{c}\text { Annual } \\
\text { Rquivalent } \\
\text { Revenue }\end{array}$ & $\begin{array}{c}\text { Average } \\
\text { Revenue }\end{array}$ & $\begin{array}{c}\text { Annual } \\
\text { Equivalent } \\
\text { Revenue }\end{array}$ & $\begin{array}{c}\text { Average } \\
\text { Revenue } \\
\text { Equivalent } \\
\text { Revenue }\end{array}$ \\
\hline \hline Biodiesel & $\$ 608.74$ & $\$ 436.46$ & $\$ 516.64$ & $\$ 370.43$ & $\$ 430.37$ & $\$ 308.57$ \\
\hline Seed meal & $\$ 487.48$ & $\$ 349.52$ & $\$ 413.72$ & $\$ 296.64$ & $\$ 344.64$ & $\$ 247.10$ \\
\hline Total revenue & $\$ 1,096.22$ & $\$ 785.98$ & $\$ 930.37$ & $\$ 667.06$ & $\$ 775.01$ & $\$ 555.68$ \\
\hline Net returns/ha yr ${ }^{-1}$ & $\$ 237.05$ & $\$ 169.96$ & $\$ 118.94$ & $\$ 85.28$ & $\$ 8.32$ & $\$ 5.96$ \\
\hline
\end{tabular}

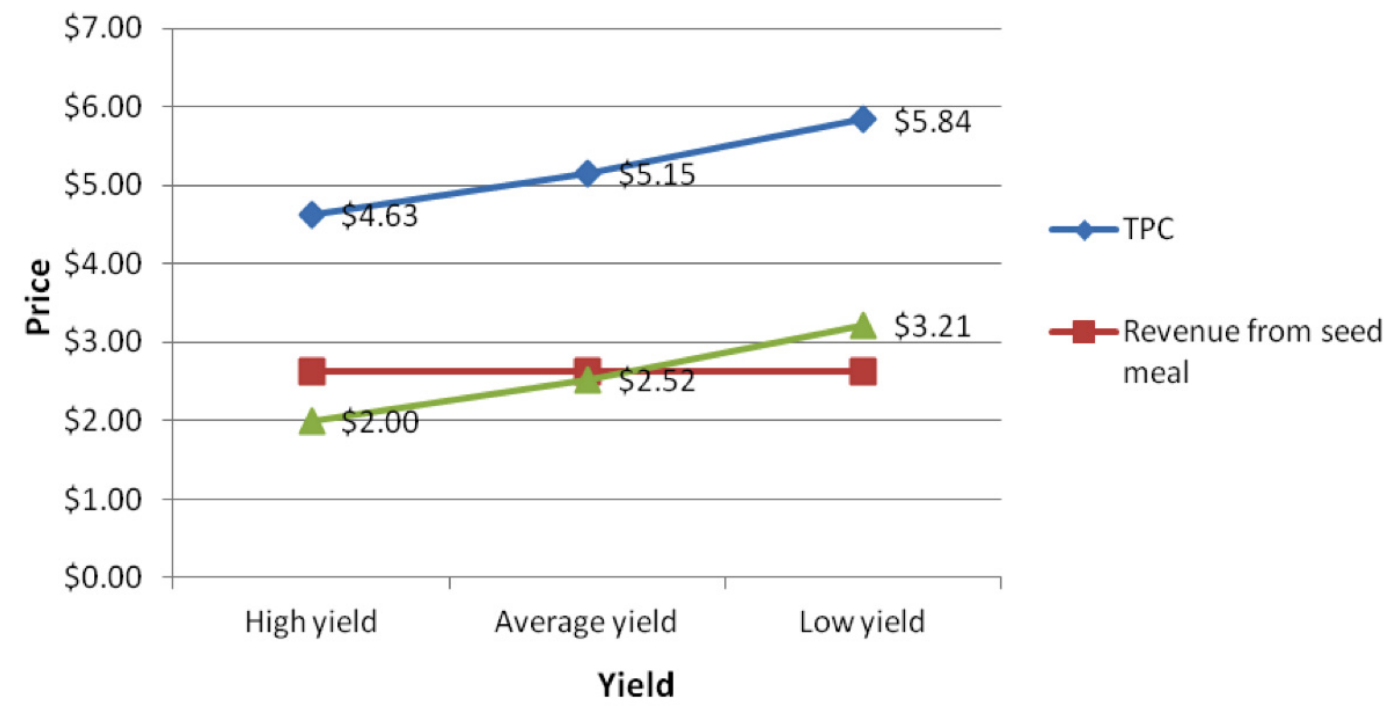

Figure 3: Net return from a gallon of biodiesel production to the producer.

$\$ 5.96 / \mathrm{ha}^{-1} \mathrm{r}^{-1}$. These findings are based on three different yield scenarios (high, medium and low) which were 2805,2381 and $1983 \mathrm{~kg} / \mathrm{ha}$ respectively.

As mentioned earlier, total production costs include seed production costs and processing costs. The estimated average sunflower seed production costs were $\$ 374.15 / \mathrm{ha} \mathrm{yr}^{-1}$. Similarly the estimated processing cost to extract biodiesel from sunflower seed were \$213.56/ha $\mathrm{yr}^{-1}$ (under the scenario of average sunflower yield and medium rate of processing). Total production cost per gallon of biodiesel varies according with various yield scenarios. Accordingly, total production cost per gallon of biodiesel from high, average and low seed yield were $\$ 4.63, \$ 5.15$ and $\$ 5.84$ respectively. The revenue from seed meal that can be obtained when producing a gallon of biodiesel was $\$ 2.63$. After considering the revenue from seed meal, the net production costs of producing a gallon of biodiesel to producer was ranged $\$ 2.00$ to $\$ 3.21$ (Figure 3).

\section{CONCLUSIONS}

This study focused biodiesel production from sunflower which is a popular summer oilseed crop in the southern plains of the U.S. The major objective of this paper was to evaluate the economic feasibility of producing biodiesel from sunflower under small-scale setting. The analysis showed the economic feasibility of investment for small scale on-farm biodiesel unit. Returns are sensitive to the farm level values (prices) of biodiesel, seed meal and value placed on crop. When revenue from the seed meal is considered, the total production cost of producing biodiesel ranges from was $\$ 2.00$ - $\$ 3.21 / \mathrm{gal}$. The finding from this study reveals sunflower as an economically important summer crop for small scale on-farm production of biodiesel. The findings further improve the understanding of growing oilseed crops and on-farm processing of oil for local biodiesel production that could play vital role in improving farm income as well as sustainable and independent energy for farmers. 


\section{REFERENCES}

[1] Fernando $\mathrm{S}$, Hall $\mathrm{C}$, Jha $\mathrm{S}$. NO $\mathrm{x}$ reduction from biodiesel fuels. Energy Fuel 2006; 20: 376-82 http://dx.doi.org/10.1021/ef050202m

[2] Demirbas, A. Global biofuel strategies. Energy Education Science and Technology 2006; 17: 27-63.

[3] Reijnders L. Conditions for the sustainability of biomass based fuel use. Energy Policy 2006, 34: 863-76. http://dx.doi.org/10.1016/.enpol.2004.09.001

[4] Puhan S, Vedaraman N, Rambrahaman BV, Nagarajan G. Mahua (Madhuca indica) seed oil: a source of renewable energy in India. Journal of thermal Science and Industrial research network JTSIR 2005; 64: 890-6.

[5] Kingwell R, Plunkett B. Economics of on- farm biofuel production. Invited paper presented at the conference. Bioenergy and Biofuels (February 2006). Perth, Australia: 2006

[6] eXtension.. Sunflowers for Biofuel Production, 2014 [cited 2014 Dec 7]: Available from: http://www.extension.org/pages/ 2933605/sunflowers-for-biofuel-production\#.VCjsluNdU_Q

[7] National Sunflower Association. All about Sunflower, Sunflower oil and statistics, 2015 [cited 2015 Apr 4]: Available from: http://www.sunflowernsa.com/all-about/ , http://www.sunflowernsa.com/oil/biodiesel/ and http://www. sunflowernsa.com/stats/historical-prices-values/

[8] Kenkel P, Holcomb R. Feasibility of on-farm or small scale oilseed processing and biodiesel production. In B. English, R. Menard, \& K. Jenson (Eds.), 2008; Proceedings of the Transition to a Bio Economy: Integration of Agricultural and Energy Systems Conference. Farm Foundation Oak Brook, IL, 49-54.

[9] Carter, R. Sunflowers: From field to fuel. Drawing the attention between diversified agriculture, renewable energy, and food production in Vermont. 2013 [cited 2014 Nov 14]: Available from: http://smallfarms.cornell.edu/2013/10/07/ sunflowers-from-field-to-fuel/

[10] USDA-NASS, Sunflower, oil: Production per harvested acre by county, 2013[cited 2015 Apr 21]: Available from: http:// www.nass.usda.gov/Charts_and_Maps/Crops_County/sfopr.asp

[11] USDA-NASS. Agricultural Prices, 2014 [cited 2015 Mar 12] Available from: http://usda.mannlib.cornell.edu/usda/nass/ AgriPric//2010s/2014/AgriPric-07-31-2014.pdf
[12] McClure MA, Allen FL, Dohnson RD, Heatherly LG. Sunflower: An Alternative Crop for Tennessee Producers Production Guidelines and Tennessee Hybrid Trials University of Tennessee Extension. SP721; 2010 [cited 2015 Feb 24[: Available from: https://utextension.tennessee.edu/ publications/Documents/SP721.pdf

[13] Stebbins, EJ. Homegrown Feed, Food and Fuel. The market potential of farm scale oilseed crop products in Vermont. Department of Community Development and Applied Economics. University of Vermont, 2008 [cited 2015 Mar 16] Available from: http://www.vsjf.org/biofuels/documents/ FFP_Final_Report_2008.pdf

[14] eXtension. Economics of small-scale biodiesel production Farm energy, 2012 [cited 2014 Nov 18]: Available from: http://www.extension.org/pages/30024/economics-of-smallscale-biodiesel-production\#.VCp3QuNdU_Q

[15] USDA-NASS. Annual statistical bulletin, 2008: [cited 2015 Mar 17]: Available from: http://www.nass.usda.gov/ Statistics_by_State/Pennsylvania/Publications/Annual_ Statistical Bulletin/2007_2008/Prices_paid.pdf

[16] DOE-EIA. Weekly Diesel Prices-All Types, March 1994January 2008. Department of Energy - Energy Information Administration, 2008 [cited 2014 Nov 17]: Available from: http://tonto.eia.doe.gov/oog/info/wohdp/diesel.asp

[17] Bachmann, J. Oilseed processing for small-scale producers ATTRA Publication \#IP134, May. ATTRA (Appropriate Technology Transfer for Rural Areas) - National Sustainable Agriculture Information Service, National Center for Appropriate Technology (NCAT), Fayetteville, AR, USA; 2004

[18] Stebbins-Wheelock, EJS, Parsons R, Wang Q, Darby $H$, Grubinger V. Technical feasibility of small-scale oilseed and on-farm biodiesel production: A Vermont case study. Journal of Extension, JOE, 2012; 50 (6) [cited 2015 Jan 25]: Available from: http://www.joe.org/ joe/2012december/pdf/ JOE_v50_6rb8.pdf

[19] Monti A, Fazio S, Lychnaras V, Soldatos P, Venturi G. A full economic analysis of switchgrass under different scenarios in Italy estimated by BEE model. Biofuels and Bioenergy, 2006; 31 177-185. http://dx.doi.org/10.1016/j.biombioe.2006.09.001

[20] DOE. Clean cities alternative fuel price report. Department of Energy, 2013 [cited 2014 Nov 12]: Available from: http://www.afdc.energy.gov/uploads/publication/alternative_f uel_price_report_oct_2013.pdf 